\title{
Capacitive earthing charge-based method for locating faults within a DC microgrid
}

\author{
Ahmad Makkieh, Abdullah Emhemed, \\ Rafael Pena-Alzola, Graeme Burt \\ Institute for Energy and Environment, University of Strathclyde, \\ Glasgow, UK, ahmad.makkieh@strath.ac.uk
}

\author{
Adria Junyent-Ferre \\ Imperial College London, UK
}

\begin{abstract}
This paper presents a new fault location method using capacitive earthing charge current combined with moving average and Savitzky-Golay filters. Locating a DC fault in a DC microgrid can be challenging due to reduced fault current magnitudes, resulting either from high resistive faults, or during the transition between grid-connected and islanded modes. The capacitive earthing method is proposed for earthing DC systems to avoid the corrosion of earthed metallic surfaces. Under different fault conditions and at different locations, the capacitive earthing with the earth path, charges a transient current with a peak value that depends on the initial voltage of the capacitor and the fault loop between the capacitor and the fault point. Therefore, this paper utilises earth capacitor prefault voltages, transient current peak and the derivative current of the capacitive earthing to estimate the total inductance of the fault loop. This in turn can be used to determine the location of DC faults. This paper also quantifies the impact that resistive faults have on the accuracy of the method, especially when the resistance of the fault dominates the total fault loop. The ability to distinguish between downstream and upstream faults with respect to the earthing point location also adds significant value to the proposed method. The proposed fault location technique is tested against pole-to-earth fault at different locations using Matlab-Simulink.
\end{abstract}

Keywords - Capacitive earthing, DC earthing Schemes, Fault current, Low voltage DC microgrid, Protection for safety

\section{INTRODUCTION}

Direct current (DC) microgrids are expected to play an important role in facilitating the connection and control of distributed energy resources (DERs) to meet future low carbon energy policy [1]. Generally speaking, DC microgrids performance under normal and faulted conditions are highly influenced by their interface to the AC grid and by their operation state grid-connected or islanded [2]. One of the remaining challenges is the requirement for accurately locating DC faults. In particular, faults with reduced fault current magnitudes which can be the result of resistive faults, and utilization of converters with fault management capabilities or caused during DC microgrid in islanded operation [3]. Effective fault location determination is one of the key criteria for designing secure and safe DC protection schemes, as well as the importance for quick maintenance and fast power cut restoration time. Until now, research has primarily focused on offline techniques for the determination of fault location [4]-[5]. Such techniques are mainly based on injecting DC voltage or signal current into the faulty cable with an additional probe power unit. In spite of the fact that these techniques can trace the location of the faulty cable, they are required to be connected to each cable section and thus increasing the overall cost of the system. Techniques for online estimation and determination of fault location are also discussed in the literature using different algorithms without the need for additional signal injection. Such techniques utilise travelling wave based methods to determine the location of the faulty cable. However, in the case of DC microgrids with small cable lengths, these methods will not provide accurate results due to the small surge reflection time [6]-[7]. In addition, a differential current based fast detection and fault location method is reported in [8]. This method relies on the current measurements from both ends of the faulty cable along a communication medium (i.e., Ethernet) and is based on the non-iterative and cumulative sum average approach to simplify the proposed protection scheme. However, this method does add extra cost to the system and could potentially influence the location results in the case of a failure in the communication link.

To address the aforementioned issues, this paper proposes an online fault location estimation scheme for a radial DC system that does not require communication or additional signal injection. This scheme considers capacitive earthing connected at the negative pole of the DC cable for a two-wire (unipolar) system. The capacitive earthing component is combined with local measurements to determine the location of the fault along with an associated estimation of error under a pole-to-earth fault condition.

The paper is organised as follows. Section II presents the implementation of the capacitive earthing scheme in a DC microgrid. In Section III, the proposed fault location method is discussed in detail. Finally, the simulation studies and conclusion of the presented work are drawn in sections IV and $\mathrm{V}$ respectively.

\section{IMPLEMENTATION OF CAPACITIVE EARTHING SCHEME}

Capacitive earthing is proposed for DC microgrids to prevent DC current leakage in the DC protective earthing conductor under normal operation and also to form a fault path during DC pole-to-earth faults only. This is essential for 
minimizing corrosion of the adjoining infrastructure. The principles of capacitive earthing scheme are detailed in the proceeding subsections.

\section{A. The steady state condition}

The advantage of implementing the capacitive earthing scheme is that the impedance to earth is limitless in the steady state condition. As a consequence, no DC earth currents can flow and thus, corrosion can be prevented. Alternatively, for high frequencies, the capacitor impedance decreases and hence, it acts as a low resistance earthing scheme for fast transients.

The impedance of a capacitor in the Laplace domain is given by:

$$
z_{c}(s)=\frac{1}{C s}
$$

\section{B. The faulted condition}

In the event of a pole-to-earth fault, the fault current will circulate through the capacitive earthing. Fig 1 illustrates the behaviour of the earthing capacitor. At $t=0$, the switch $\mathrm{S}$ closes and current flows into the capacitor, which initiates charging. In this circuit it is assumed that the capacitor $\mathrm{Ce}$ is initially discharged. The resistor, $R_{f}$, represents the fault resistance and the charging behaviour of the capacitor is described in (2) and (3):

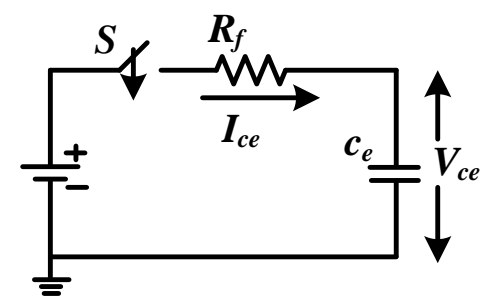

Fig. 1.Equivalent circuit for charging the capacitive earthing

$$
\begin{gathered}
v_{c e}(t)=v\left(1-e^{\frac{-t}{\tau}}\right), \quad \tau=R_{f} C_{e} \\
i_{c e}(t)=C_{e} \frac{d v_{c e}(t)}{d t}=\frac{V}{R_{f}} e^{\frac{-t}{\tau}}
\end{gathered}
$$

Where $V_{c e}$ is the voltage across the capacitive earthing, $I_{C e}$ is instantaneous current flow through the capacitive earthing and $\tau$ is the time constant.

Indeed, charging the capacitor will cause a voltage swing in the whole network and therefore it is necessary to clamp the voltage across the capacitor to prevent a complete charging of the capacitor. This can be done with the help of a voltage clamp which will be described in the following subsection.

\section{Voltage clamping}

A voltage clamp is added in parallel with the capacitive earthing as shown in Fig 2. The voltage clamp can be made of a string of diodes connected in parallel with the capacitive earthing. When a fault occurs in the network, and before it is isolated, the capacitive earthing will keep charging. If nothing is done to prevent this phenomenon, the voltage could reach the value of the voltage across the fault itself. By adding a voltage clamp, the voltage across the capacitive earthing is controlled. Once the capacitor voltage reaches the clamp voltage, the diode will begin conducting but will restrain the voltage across the capacitor from rising any further. Obviously, once the diode is conducting, it is the equivalent of having a low resistance earthing scheme. At this point, the source is earthed through the diode and all the fault current flows through the diode. The clamp voltage is calculated in this paper with assumption that the biggest allowable deviation on the poles is $5 \%$ of the nominal voltage $(350 \mathrm{~V})-$ in this case, $\pm 17.5 \mathrm{~V}$. The clamp voltage must then be at least $17.5 \mathrm{~V}$.

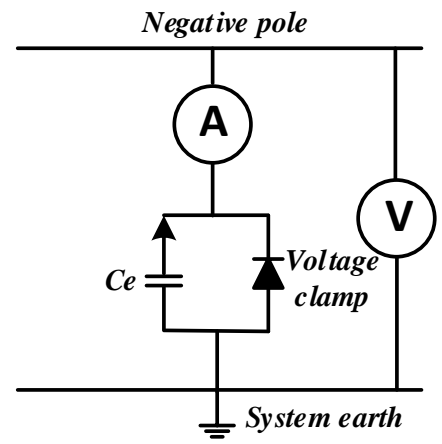

Fig. 2. Voltage clamp in parallel with the capacitive earthing

\section{Size of the capacitor}

It is important to size the capacitive earthing correctly in the network to provide the protection device enough time to isolate the fault before the capacitor is charged to clamp voltage. Otherwise, the voltage clamp (i.e., diode) would conduct at some point during the occurrence of the fault. It is therefore desirable to keep the capacitive earthing effective in the network to prevent the occurrence of this phenomenon. With the help of the standard IEC 60479-1 which defines the maximum time of operation for protection devices to trigger for each fault current, the size of the capacitive earthing of the network is calculated. Knowing this information, it can be ensured that the capacitive earthing is kept charging even after the occurrence of the fault and can prevent it from reaching the clamping voltage. Several assumptions have been made to calculate the size of the capacitive earthing:

- The maximum fault path resistance is chosen to be the upper value of the body impedance $(1050 \Omega)$

- The total inductance of the fault loop, including the cables and the protective relays, are neglected. By doing this, the calculation is more conservative and, as a side benefit, the calculation is easier and requires less information

- The voltage across the fault depends on the load connected to the faulted pole and is considered to be the nominal pole voltage

- The fault current is assumed constant in the calculation but not in the simulation 
The size of the capacitive earthing as in (6) can be calculated for each time current by using (2) coupled with the following equations (4) and (5):

$$
\begin{gathered}
v=v_{f}=R_{f} \cdot I_{f}=v_{\text {nom }} \\
v_{\text {ce max }}=v_{\text {clamp }} \\
C_{e}=\frac{-t \max }{R_{f}} * \frac{1}{\ln \left(1-\frac{v_{\text {clamp }}}{v_{f}}\right)}
\end{gathered}
$$

Where $V_{\text {clamp }}$ is the voltage across the diode, $V_{f}$ is voltage across the fault, and $t_{\max }$ is the maximum time for the protection to operate.

From the calculation shown in Table I, the size of the capacitive earthing is $3.7 \mathrm{mF}$. Indeed, increasing the capacitance will bring more stability to the network, yet at an increased expense.

TABLE I: THE CAPACITIVE EARTHING CALCULATION RESULT
\begin{tabular}{|c|c|c|c|c|c|}
\hline $\begin{array}{c}\text { Vf } \\
{[\mathbf{V}]}\end{array}$ & $\begin{array}{c}\mathbf{I f} \\
{[\mathbf{A}]}\end{array}$ & $\begin{array}{c}\mathbf{R f} \\
{[\mathbf{\Omega}]}\end{array}$ & $\begin{array}{c}\text { Tmax } \\
{[\mathbf{s}]}\end{array}$ & $\begin{array}{c}\text { Vclamp } \\
{[\mathbf{V}]}\end{array}$ & $\begin{array}{c}\mathbf{C e} \\
{[\mathbf{F}]}\end{array}$ \\
\hline 350 & 0.333 & 1050 & 0.2 & 17.5 & 0.003713 \\
\hline
\end{tabular}

\section{PROPOSED FAULT LOCATION METHOD}

The proposed fault location method is based on the concept that, when the DC fault occurs, the capacitive earthing within the earth path starts charging a transient current. This charge current does not increase instantaneously but instead, its initial rate of change is dependent on the voltage across on the capacitive earthing and the fault path inductance. With knowledge of the inductance per unit length of the cable $(\mathrm{mH} / \mathrm{km})$, the distance from the capacitive earthing to the fault location can be calculated as in (13). Provided that di/dt can be measured, the inductance $\mathrm{L}$ can also be determined. The estimation of the fault loop resistance is not chosen as the basis for locating the DC fault due to the variation of fault resistance with fault distance.

To accurately estimate the inductance between the capacitive earthing and the fault, the Moor-Penrose pseudo inverse technique is implemented to estimate the inductance based fault location. This technique is established from the least squares problem for a system of linear equations without a unique solution. It provides relatively accurate results for estimating the fault location compared with conventional iterative fault location estimators, where a number of the samples (i.e. local voltages and currents measurement) are available before calculation. Generally speaking, the measurement accuracy of the voltage and the current signals and their associated derivatives influence the estimation of the fault localisation result. Therefore, filters and smoothers such as moving average and Savitzky-Golay filters are proposed in the estimation process, to not only reduce noise, but also to maintain the shape and height of the waveform peaks.

\section{A. Moving average smoothing filter}

An online moving average filter is the most common filter in analysing a random noisy signal. A moving average filter operates by averaging a set of data points from the input signal to create each point in the output signal as in (7) [9]. This operation is repeated with a window length of $\mathrm{M}$ (the number of points in the average) points to calculate the average of the data set.

$$
y[n]=\frac{1}{M} \sum_{j=0}^{M-1} x[n-j]
$$

Where $x[n]$ is the input signal and $y[n]$ is the output signal.

In this paper, a digital differentiator is implemented numerically with a moving average filter to obtain $\mathrm{di} / \mathrm{dt}$. The current derivative is achieved with a first order approximation method as in (8)

$$
\frac{d_{i(k)}}{d_{t}}=\frac{i(k+1)-i(k)}{T}
$$

Where $\frac{d_{i(k)}}{d_{t}}$ is the current derivative at interval $k, i(k)$ is the measured current at interval $k$ and $T$ is the sampling period.

\section{B. Savitzky-Golay smoothing filter}

The Savitzky-Golay filter is a method of smoothing and differentiating the noisy data obtained from the measurement devices on the basis of a local least squares polynomial approximation [10]. A window with a length of $N=2 M+1$ samples around the central of the data point is used. A polynomial of order $p$ is fitted to the samples within the window in order to minimise the mean squared error as in (9) and (10)

$$
\begin{gathered}
\varepsilon_{n}=\sum_{i=-M}^{M}(q(i)-x(i))^{2} \\
q(i)=\sum_{k=0}^{p} a_{k} i^{k}
\end{gathered}
$$

Where $p=$ polynomial order, $k=(0, \cdots \cdots, \mathrm{n})$ and $a_{k}$ is $k^{t h}$ coefficient of polynomial.

A polynomial coefficient vector $a=\left[a_{0}, a_{1}, a_{2}, \ldots \ldots a_{n}\right]^{T}$, input samples vector $x=\left[x_{-M}, \ldots . x_{-1}, x_{0}, x_{1} \ldots \ldots x_{M}\right]^{T}$, and for $p<2 M+1$, the coefficient $a$ can be obtained:

$$
a=\left(A^{T} \cdot A\right)^{-1} \cdot A^{T} \cdot x=H \cdot x
$$

Where $A=\left[\begin{array}{ccccc}(-M)^{0} & (-M)^{1} & \ldots & \ldots & (-M)^{n} \\ \vdots & \vdots & \vdots & \vdots & \vdots \\ (-1)^{0} & (-1)^{0} & \ldots & \ldots & (-1)^{0} \\ 1 & 0 & \ldots & \ldots & 0 \\ (M)^{0} & (M)^{1} & \ldots & \ldots & (M)^{n}\end{array}\right]$ 
Note that it is only required to compute $a_{0}$, thus calculating the first row of matrix $H$ is sufficient. The coefficient $a_{0}$ represents the smooth value of $x_{0}$ at $M=0$. An interesting property of Savitzky-Golay filter is that they can be used to obtain a smoothed version of the derivative of $x(i)$.This can be done by multiplying the first row of matrix $H$ with the vector of samples $x$ to obtain the coefficient $a_{1}$ and thus, di/dt can be calculated.

\section{Simplified equivlent circuit of a DC faulted feeder}

A simplified unipolar DC feeder connected to a DC source and suppling a DC load is used to explain the principle of the proposed method. The negative pole of the circuit is connected to the earth through a diode in parallel with a capacitor as shown in Fig 3. The state space equation for this circuit is written as:

$$
v_{d c}+v_{c e}=L \frac{d i_{c e}}{d t}+\left(R+R_{f}\right) i_{c e}
$$

Where $V_{d c}$ is the input DC voltage, $V_{c e}$ is the voltage across the capacitive earthing, $I_{C e}$ is instantaneous current flow through the capacitive earthing. $R_{H}$ and $L_{H}$ are the resistance and inductance of the positive pole respectively, while $R_{L}$ and $L_{L}$ are the resistance and inductance of the negative pole respectively. $C_{\mathrm{e}}$ and $R_{f}$ are the capacitive earthing point and fault resistance respectively.

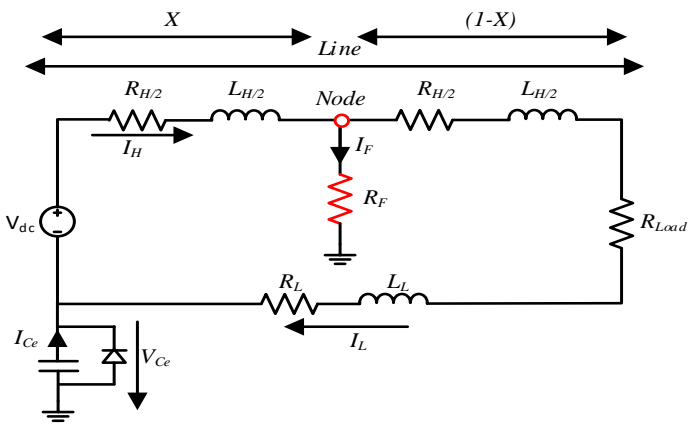

Fig. 3. A faulted DC feeder with positive earth fault condition

During a pole-to-earth fault path, the capacitive earthing acts as a low resistance resulting in a more resistive $R_{f}$ path and hence capacitive earthing charging takes place through the diode and $R_{f}$. The amount of capacitive charge current flowing will depend on the size of the capacitive earthing impedance, $X_{c}$. The longer the cable distance, the lower the peak current charging level but the longer the charging period will be.

\section{Fault distance estimation}

The differential equation expressed in (13) is used for estimating the fault location proposed for a DC microgrid and can be rewritten in matrix form in terms of the number of measurement samples, $\mathrm{N}$ :

$$
B=A \cdot\left[\begin{array}{c}
L \\
R+R_{f}
\end{array}\right]
$$

$$
A=\left[\begin{array}{cc}
\frac{d i_{c e}}{d t}(0) & i(0) \\
\cdot & \cdot \\
\cdot & \cdot \\
\frac{d i_{c e}}{d t}(N) & i(N)
\end{array}\right], B=\left[\begin{array}{c}
V_{d c}+V_{c e}(0) \\
\cdot \\
\cdot \\
V_{d c}(N)+V_{c e}(N)
\end{array}\right]
$$

The unknown resistance, $\mathrm{R}$, and inductance, $\mathrm{L}$, are calculated by the pseudo inverse technique as in (16)

$$
\left[\begin{array}{c}
L \\
R+R_{f}
\end{array}\right]=\left(A^{T} \cdot A\right)^{-1} \cdot A^{T} \cdot B
$$

Once a fault is detected by overcurrent protection, the inductance based fault location method is triggered. The voltage, current and its derivative are captured and sampled at each time step. The current derivative is filtered using moving average and Savitzky-Golay filters and is calculated once the current signal measurement is available. Following that, a least squares method is used to estimate the corresponding inductance from the capacitive earthing to the fault point. Subsequently, the distance is calculated using the estimated inductance value.

\section{MODELLING AND SIMULATION STUDIES}

This section includes comparative analysis of estimating the inductance-based fault location method. The proposed fault location method is assessed using relative errors under different fault conditions and verified for various earthing resistances and fault distances by calculations using MATLAB/Simulink simulations.

\section{A. DC microgrid test network}

The system under study is a typical DC microgrid network as depicted in Fig 4. The DC network is connected to an AC grid supply point through a two-level VSC and transformer. A Battery Energy Storage System (BESS) is connected to the DC Point of Common Coupling (PCC), and has been set to maintain a DC voltage at the PCC to enable stable operation of the DC microgrid in both grid-connected and islanded modes of operation. A lumped DC load is connected to the DC bus. An earthing point of a capacitor in parallel with a diode is used for earth fault detection and personal safety. The DC microgrid test system parameters are illustrated in Table II.

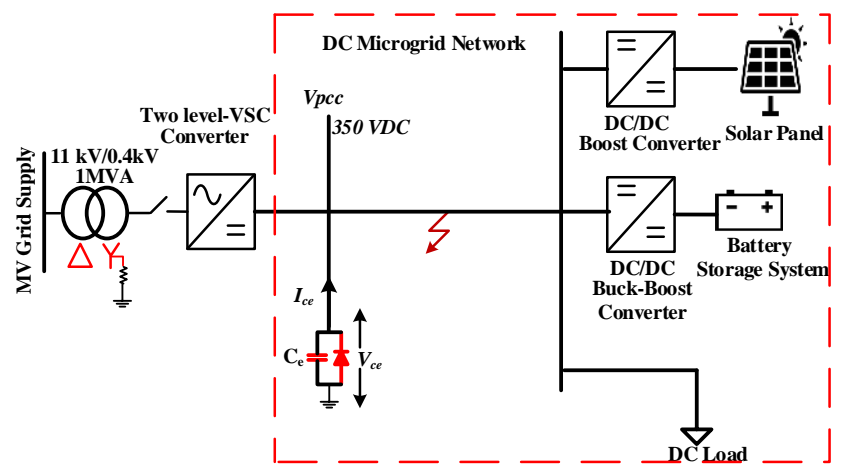

Fig. 4.DC microgrid test network 
TABLE II: AC AND DC NETWORK PARAMETERS

\begin{tabular}{|c|c|}
\hline Parameter & Value \\
\hline AC supply $[\mathrm{kV}]$ & 11 \\
\hline Transformer voltage ratio $[\mathrm{kV}]$ & $11 / 0.350$ \\
\hline LVDC main voltage $[\mathrm{V}]$ & $350 \mathrm{~V}$ (pole-to-pole) \\
\hline R and L of LVDC cable & $0.164 \Omega / \mathrm{km}, 0.14 \mathrm{mH} / \mathrm{km}$ \\
\hline Cable length $[\mathrm{Km}]$ & $1 \mathrm{~km}$ \\
\hline PV generation $[\mathrm{kW}]$ & $10 \mathrm{~kW}$ \\
\hline Battery system $[\mathrm{kWh}]$ & $7.8 \mathrm{kWh}$ \\
\hline DC loads $[\mathrm{kW}]$ & $5 \mathrm{~kW}$ \\
\hline
\end{tabular}

\section{B. Cable ground fault location analysis}

The calculation to find the location (i.e., inductance value) of the cable earth fault is implemented with moving average and Savitzky-Golay filters within a window consisting of a set of eleven measurements. The cable length is assumed to be $1 \mathrm{~km}$. The proposed method is tested under various earth resistances and fault distances.

\section{1) Fault locations with directly calculation method}

In this case, the actual inductance value is calculated directly using (13). The variation of fault resistance $R_{f}$ and distance (i.e., $0.1-2 \Omega$ and $0.5-1 \mathrm{~km}$, respectively) are considered for this case, as well as the pole-to-earth fault initiated in middle of the DC cable. Due to the small inductance compared with the large earth fault resistance, the calculation errors for inductance increase dramatically when the earth fault resistance dominates the fault loop as shown in Table III and Table IV. The maximum percentage error is calculated for a pole-to-earth fault with a moving average filter as $139.8 \%$ for $R_{f}=2 \Omega$ as shown in Fig 5(a). Whereas, using the Savitzky Golay filter, the maximum percentage error is calculated for pole-to-earth fault as $140.8 \%$ for $\mathrm{R}_{\mathrm{f}}=2 \Omega$ as shown in Fig 5(b). The time response obtained from the calculation is listed in Table VII, which shows that the further the fault occurs from the capacitive earthing point, the faster the calculation. In this proposed method, the time response is in order of microseconds, even for the smallest earth fault resistance. This means the DC circuit breaker has enough time to operate after the measurements and calculations of captured data have been completed.

\section{2) Fault locations with least squares method}

In this case, a least squares method is utilised to minimize the calculation error for estimation of the inductance value. Therefore, by choosing a pseudo inverse technique, the error in the estimation of inductance is reduced and hence, an improved estimation of the fault location can be achieved. The improved inductance estimation results are listed in Table V and Table VI. The maximum percentage error is calculated for a pole-to-earth fault with a moving average filter as $6.52 \%$ for $\mathrm{R}_{\mathrm{f}}=2 \Omega$ as shown in Fig 6(a). Whereas, using the Savitzky Golay filter, the maximum percentage error is calculated for pole-to-earth fault as $7.28 \%$ for $R_{f}=2 \Omega$ as shown in Fig 6(b). In spite of a lower accuracy, the Savitzky-Golay filter presented some advantages in terms of the response time. The percentage error is calculated as in (17).

$$
\% \varepsilon=\left[\frac{l_{c a l}-l_{a c t}}{l_{\text {act }}}\right] * 100
$$

Where $l_{c a l}$ is calculated inductance and $l_{a c t}$ is actual inductance

TABLE III: POLE-TO-EARTH FAULT INDUCTANCE ESTIMATION ERROR USING MOVING AVERAGE FILTER CALCULATION METHOD (IN PERCENT)

\begin{tabular}{|c|c|c|c|c|c|}
\hline Distance & $\begin{array}{c}\boldsymbol{R}_{\boldsymbol{F}}=\mathbf{0 . 1} \\
\mathbf{\Omega}\end{array}$ & $\begin{array}{c}\boldsymbol{R}_{\boldsymbol{F}}=\mathbf{0 . 5} \\
\mathbf{\Omega}\end{array}$ & $\begin{array}{c}\boldsymbol{R}_{\boldsymbol{F}}=\mathbf{\Omega} \\
\mathbf{\Omega}\end{array}$ & $\begin{array}{c}\boldsymbol{R}_{\boldsymbol{F}}=\mathbf{1 . 5} \\
\mathbf{\Omega}\end{array}$ & $\begin{array}{c}\boldsymbol{R}_{\boldsymbol{F}}=\mathbf{2} \\
\mathbf{\Omega}\end{array}$ \\
\hline $0.5 \mathrm{Km}$ & 8.6 & 27.28 & 57.62 & 94.18 & 139.8 \\
\hline $0.6 \mathrm{Km}$ & 12.53 & 27.78 & 53.45 & 83.5 & 119.83 \\
\hline $0.7 \mathrm{Km}$ & 12.41 & 21.31 & 37.21 & 55.85 & 75.85 \\
\hline $0.8 \mathrm{Km}$ & 8.83 & 15.21 & 28 & 36.87 & 48.62 \\
\hline $0.9 \mathrm{Km}$ & 7 & 13.11 & 21.11 & 30 & 38.88 \\
\hline $1 \mathrm{Km}$ & 6.7 & 9.9 & 17.3 & 24.3 & 31.1 \\
\hline
\end{tabular}

TABLE IV: POLE-TO-EARTH FAULT INDUCTANCE ESTIMATION ERROR USING SAVITZKY-GOLAY FILTER CALCULATION METHOD (IN PERCENT)

\begin{tabular}{|c|c|c|c|c|c|}
\hline Distance & $\begin{array}{c}\boldsymbol{R}_{\boldsymbol{F}}=\mathbf{0 . 1} \\
\mathbf{\Omega}\end{array}$ & $\begin{array}{c}\boldsymbol{R}_{\boldsymbol{F}}=\mathbf{0 . 5} \\
\mathbf{\Omega}\end{array}$ & $\begin{array}{c}\boldsymbol{R}_{\boldsymbol{F}}=\mathbf{1} \\
\mathbf{\Omega}\end{array}$ & $\begin{array}{c}\boldsymbol{R}_{\boldsymbol{F}}=\mathbf{1 . 5} \\
\mathbf{\Omega}\end{array}$ & $\begin{array}{c}\boldsymbol{R}_{\boldsymbol{F}}=\mathbf{\Omega} \\
\mathbf{\Omega}\end{array}$ \\
\hline $0.5 \mathrm{Km}$ & 8.6 & 27.4 & 57.96 & 94.8 & 140.8 \\
\hline $0.6 \mathrm{Km}$ & 12.6 & 27.93 & 53.76 & 84 & 120.66 \\
\hline $0.7 \mathrm{Km}$ & 12.48 & 21.45 & 37.47 & 56.28 & 76.42 \\
\hline $0.8 \mathrm{Km}$ & 8.91 & 16.1 & 28.25 & 37.25 & 49 \\
\hline $0.9 \mathrm{Km}$ & 7.07 & 13.22 & 21.33 & 30.33 & 39.33 \\
\hline $1 \mathrm{Km}$ & 6.7 & 10 & 17.5 & 24.6 & 31.5 \\
\hline
\end{tabular}

TABLE V: POLE-TO-EARTH FAULT INDUCTANCE ESTIMATION ERROR USING MOVING AVERAGE FILTER WITH LEAST SQUARES METHOD (IN PERCENT)

\begin{tabular}{|c|c|c|c|c|c|}
\hline Distance & $\begin{array}{c}\boldsymbol{R}_{\boldsymbol{F}}=\mathbf{0 . 1} \\
\mathbf{\Omega}\end{array}$ & $\begin{array}{c}\boldsymbol{R}_{\boldsymbol{F}}=\mathbf{0 . 5} \\
\mathbf{\Omega}\end{array}$ & $\begin{array}{c}\boldsymbol{R}_{\boldsymbol{F}}=\mathbf{1} \\
\mathbf{\Omega}\end{array}$ & $\begin{array}{c}\boldsymbol{R}_{\boldsymbol{F}}=\mathbf{1 . 5} \\
\mathbf{\Omega}\end{array}$ & $\begin{array}{c}\boldsymbol{R}_{\boldsymbol{F}}=\mathbf{2} \\
\mathbf{\Omega}\end{array}$ \\
\hline $0.5 \mathrm{Km}$ & 0.28 & 1.5 & 3.18 & 4.8 & 6.52 \\
\hline $0.6 \mathrm{Km}$ & 0.26 & 1.53 & 3.13 & 4.78 & 6.46 \\
\hline $0.7 \mathrm{Km}$ & 0.25 & 1.51 & 3.12 & 4.77 & 6.42 \\
\hline $0.8 \mathrm{Km}$ & 0.25 & 1.42 & 3.13 & 4.7 & 6.35 \\
\hline $0.9 \mathrm{Km}$ & 0.25 & 1.53 & 3.15 & 4.77 & 6.4 \\
\hline $1 \mathrm{Km}$ & 0.3 & 1.6 & 3.2 & 4.8 & 6.4 \\
\hline
\end{tabular}

TABLE VI: POLE-TO-EARTH FAULT INDUCTANCE ESTIMATION ERROR USING SAVITZKY-GOLAY FILTER WITH LEAST SQUARES METHOD (IN PERCENT)

\begin{tabular}{|c|c|c|c|c|c|}
\hline Distance & $\begin{array}{c}\boldsymbol{R}_{\boldsymbol{F}}=\mathbf{0 . 1} \\
\mathbf{\Omega}\end{array}$ & $\begin{array}{c}\boldsymbol{R}_{\boldsymbol{F}}=\mathbf{0 . 5} \\
\mathbf{\Omega}\end{array}$ & $\begin{array}{c}\boldsymbol{R}_{\boldsymbol{F}}=\mathbf{1} \\
\mathbf{\Omega}\end{array}$ & $\begin{array}{c}\boldsymbol{R}_{\boldsymbol{F}}=\mathbf{1 . 5} \\
\mathbf{\Omega}\end{array}$ & $\begin{array}{c}\boldsymbol{R}_{\boldsymbol{F}}=\mathbf{2} \\
\mathbf{\Omega}\end{array}$ \\
\hline $0.5 \mathrm{Km}$ & 0.3 & 1.62 & 3.34 & 5.1 & 7.28 \\
\hline $0.6 \mathrm{Km}$ & 0.3 & 1.63 & 3.33 & 5.05 & 6.81 \\
\hline $0.7 \mathrm{Km}$ & 0.31 & 1.62 & 3.31 & 5.01 & 6.74 \\
\hline $0.8 \mathrm{Km}$ & 0.31 & 1.56 & 3.31 & 4.95 & 6.65 \\
\hline $0.9 \mathrm{Km}$ & 0.32 & 1.65 & 3.32 & 5 & 6.67 \\
\hline $1 \mathrm{Km}$ & 0.3 & 1.7 & 3.3 & 5 & 6.7 \\
\hline
\end{tabular}

TABLE VII: CALCULATION TIME WITH FAULT RESISTANCE VARIATION (IN MICROSECOND)

\begin{tabular}{|c|c|c|c|c|c|}
\hline Distance & $\begin{array}{c}\boldsymbol{R}_{\boldsymbol{F}}=\mathbf{0 . 1} \\
\mathbf{\Omega}\end{array}$ & $\begin{array}{c}\boldsymbol{R}_{\boldsymbol{F}}=\mathbf{0 . 5} \\
\mathbf{\Omega}\end{array}$ & $\begin{array}{c}\boldsymbol{R}_{\boldsymbol{F}}=\mathbf{1} \\
\mathbf{\Omega}\end{array}$ & $\begin{array}{c}\boldsymbol{R}_{\boldsymbol{F}}=\mathbf{1 . 5} \\
\mathbf{\Omega}\end{array}$ & $\begin{array}{c}\boldsymbol{R}_{\boldsymbol{F}}=\mathbf{2} \\
\mathbf{\Omega}\end{array}$ \\
\hline $0.5 \mathrm{Km}$ & 250 & 200 & 200 & 200 & 200 \\
\hline $0.6 \mathrm{Km}$ & 250 & 200 & 200 & 200 & 200 \\
\hline $0.7 \mathrm{Km}$ & 200 & 150 & 150 & 150 & 150 \\
\hline $0.8 \mathrm{Km}$ & 120 & 100 & 100 & 100 & 120 \\
\hline $0.9 \mathrm{Km}$ & 80 & 80 & 80 & 80 & 80 \\
\hline $1 \mathrm{Km}$ & 65 & 50 & 60 & 60 & 60 \\
\hline
\end{tabular}




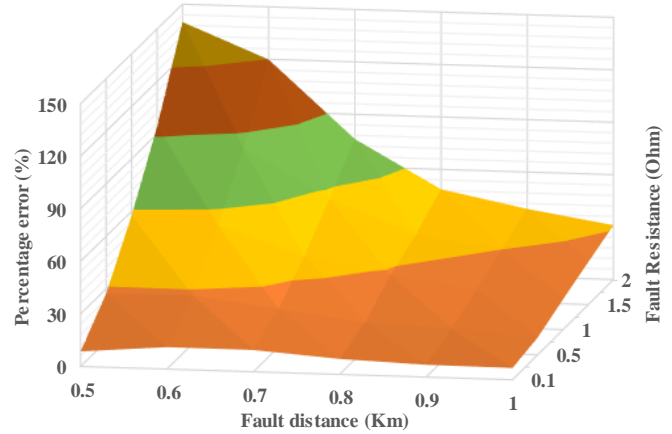

(a)
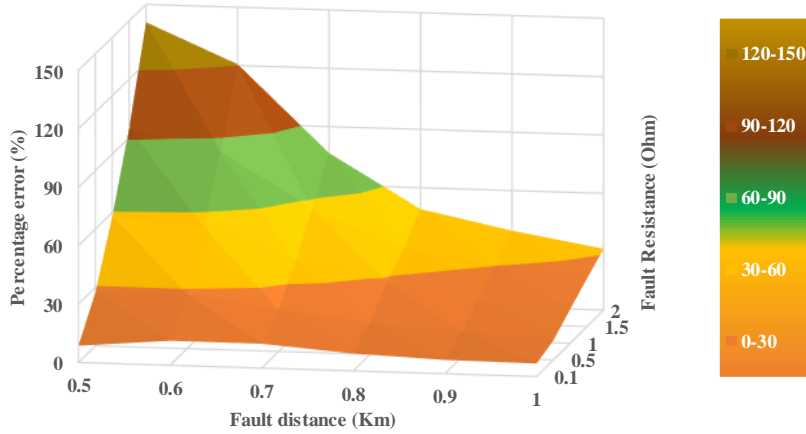

(b)

Fig. 5.Percentage error variation with fault distance and $R_{f}$ with calculation method : a) Moving averag filter ,b) Savitzky-Golay filter
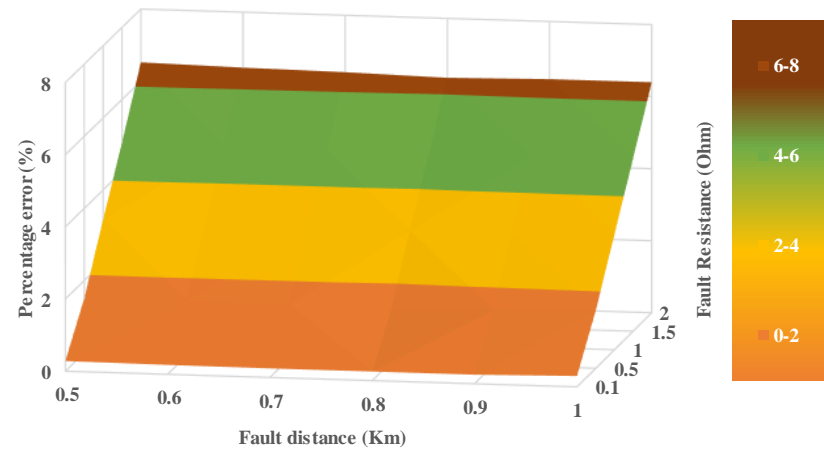

(a)

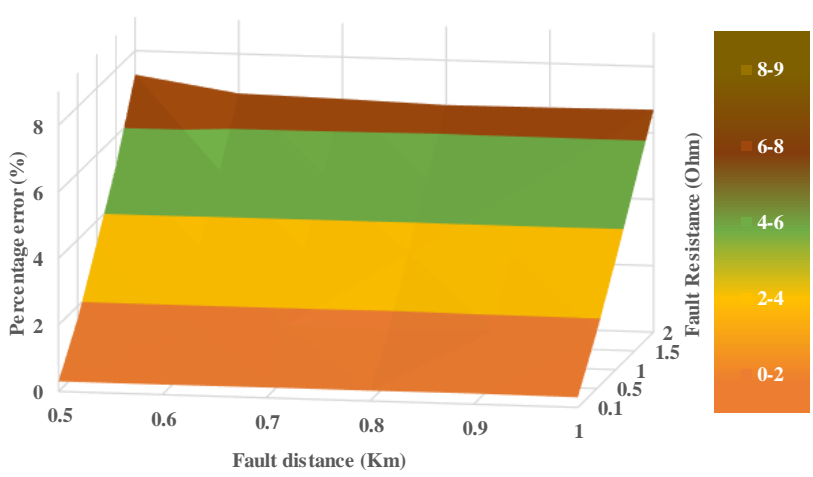

(b)

Fig. 6.Percentage error variation with fault distance and $\mathrm{Rf}$ with least squares method : a) Moving averag filter ,b) Savitzky-Golay filter

\section{CONCLUSIONS}

A new fault location scheme using capacitive earthing is proposed in this paper. This method provides sufficient information among the relationship between the capacitive earthing transient current and fault distance for locating DC earth faults. The proposed method was evaluated under a pole-to-earth fault with various fault resistances and the following observations are made:

- The developed online estimation method does not require an external signal injector. This results in a reduced operational cost and allows for locating the fault while the system remains operational both under grid-connected and islanded modes

- Estimating the inductance value directly combined with the moving average and Savitzky-Golay filters, the relative errors increase drastically with growing fault resistance. This will in turn cause the protection to mal-operate

- Using the inductance estimation scheme based on the Moore-Penrose pseudo inverse technique and combined with the moving average and SavitzkyGolay filters, the accuracy of the calculation improves significantly from $140 \%$ to $6.5 \%$ with $\mathrm{Rf}=2 \Omega$. This results in an enhanced the determination of the fault location

Finally, the method has demonstrated its credibility for locating DC faults at different locations and with different fault resistances.

\section{REFERENCES}

Q. Deng, "Fault Protection in DC Microgrids Based on Autonomous Operation of All Components," ProQuest Diss. Theses, p. 110, 2017.

A. Makkieh, A. Emhemed, and A. Junyent-Ferre, "Fault Characterisation of a DC Microgrid with Multiple Earthing under Grid Connected and Islanded Operations," in 2018 53rd International Universities Power Engineering Conference (UPEC), 2018, pp. 1-6.

R. M. Cuzner and G. Venkataramanan, "The status of DC microgrid protection," in Conference Record - IAS Annual Meeting (IEEE Industry Applications Society), 2008.

J. Do Park, J. Candelaria, L. Ma, and K. Dunn, "DC ring-bus microgrid fault protection and identification of fault location," IEEE Trans. Power Deliv., 2013.

R. Mohanty, U. S. M. Balaji, and A. K. Pradhan, "An Accurate Noniterative Fault-Location Technique for Low-Voltage DC Microgrid," IEEE Trans. Power Deliv., 2016.

O. M. K. K. Nanayakkara, A. D. Rajapakse, and R. Wachal, "Traveling-wave-based line fault location in star-connected multiterminal HVDC systems," IEEE Trans. Power Deliv., 2012.

N. K. Chanda and Y. Fu, "ANN-based fault classification and location in MVDC shipboard power systems," in NAPS 2011 43rd North American Power Symposium, 2011

S. Dhar, R. K. Patnaik, and P. K. Dash, "Fault Detection and Location of Photovoltaic Based DC Microgrid Using Differential Protection Strategy," IEEE Trans. Smart Grid, 2018.

[9] H. Azami, K. Mohammadi, and B. Bozorgtabar, "An Improved Signal Segmentation Using Moving Average and Savitzky-Golay Filter," J. Signal Inf. Process., vol. 03, no. 01, pp. 39-44, 2012.

[10] M. Sadeghi and F. Behnia, "Optimum window length of SavitzkyGolay filters with arbitrary order," Aug. 2018. 